\title{
Perception of Potential Health Risk of Climate Change and Utilization of Fans and Air Conditioners in a Representative Population of Hong Kong
}

\author{
Yang Gao $^{1} \cdot$ Emily Y. Y. Chan ${ }^{2} \cdot$ Holly C. Y. Lam ${ }^{2} \cdot$ Aiwei Wang'
}

Published online: 21 February 2020

(C) The Author(s) 2020

\begin{abstract}
Climate change, especially as reflected in heat waves, is a rising threat worldwide. Appropriate use of cooling devices can protect people from health impacts during a heat wave. A population-based telephone survey was conducted in a representative sample of residents in Hong Kong to investigate ownership and use of domestic cooling devices, identify correlates, and examine their associations with risk perception of potential health impact of climate change. More than $90 \%$ of the 1002 respondents owned and used cooling devices at home. The majority $(57.7 \%)$ perceived the potential health risk of climate change at a high level. However, risk perception had no relationship with ownership and utilization of cooling devices. Old people ( $\geq 65$ years), the low-educated, those with low income, and those with chronic diseases were more likely not to use air conditioners when feeling hot. Our findings suggest that there are no signs showing people have taken more protective actions although half of respondents recognized climate change as a threat. Familial economic condition may be a major determinant in ownership and use of air conditioners at home. Old people and those with chronic diseases are at high risk of adverse exposure to climate change and therefore should be equipped with appropriate measures to use cooling devices.
\end{abstract}

Emily Y. Y. Chan

emily.chan@cuhk.edu.hk

1 Department of Sport and Physical Education, Hong Kong Baptist University, Hong Kong, China

2 Collaborating Centre for Oxford University and CUHK for Disaster and Medical Humanitarian Response, The Jockey Club School of Public Health and Primary Care, The Chinese University of Hong Kong, Hong Kong, China
Keywords Climate change - Domestic cooling device $\cdot$ Heat wave health impact $\cdot$ Hong Kong $\cdot$ Risk perception

\section{Introduction}

Climate change, mostly reflected by increased occurrences of extreme hot or cold weather, is a major public health threat to urban communities globally. Heat waves, although there is no universal definition, are understood to be hot weather events that breach regional or national thresholds and last for several days (Gupta et al. 2012). According to the Intergovernmental Panel on Climate Change (IPCC), heat waves are likely to occur with increasing frequency in some parts of the world as a result of climate change (IPCC 2012). Climate modelling undertaken by the IPCC has suggested "a 1 -in-20 year hottest day is likely to become a 1 -in-2 year event by the end of the twenty-first century in most regions, except in the high latitudes of the Northern Hemisphere, where it is likely to become a 1-in-5 year event" (IPCC 2012, p. 13). Compared to preindustrial levels in 1850-1900, elevated global surface temperature hit $1^{\circ} \mathrm{C}$ in 2017 , with an increasing rate of $0.2{ }^{\circ} \mathrm{C}$ per decade (IPCC 2018).

The rising trend of heat waves has resulted in much heat-related illness and deaths. Famous heat waves occurred across Europe in August 2003 when unprecedented high temperatures for 3 weeks resulted in more than 15,000 excess deaths in France and an estimated 30,000 across Europe (Fouillet et al. 2008; Robine et al. 2008). A recent global analysis on heat-related mortality reported between 1980 and 2014 indicated that currently about 30\% of the entire human population was exposed to potentially deadly heat at least 20 days per year (Mora et al. 2017). The 
projected figure by 2100 would hit $74 \%$ if greenhouse gas emissions keep growing at the current rate. Urban residents are more vulnerable to the health impacts of heat waves due to the existence of urban heat islands, in particular those individuals and communities living in poverty (IPCC 2018). In addition, risk for some vector-borne infectious diseases (for example, malaria and dengue fever) are also expected to elevate along with global warming. In 2015, the United Nations, in Sustainable Development Goal 13 (SDG 13), called for urgent global action to combat climate change and its impacts by 2030 (UN General Assembly 2015). The SDG 13 is intrinsically linked to all 16 of the other SDGs. For instance, the SDG 3 (Health) commits all countries to strengthen their national capacities for early warning, risk reduction, and global health risks and to substantially reduce mortality from air, water, and soil pollution (UN General Assembly 2015). The Asia-Pacific region, as one of the most vulnerable regions to pollution impacts, needs to make more efforts against climate change.

People are not evenly affected by heat waves. Previous studies have identified some risk and protective factors. Urban residents, poor and disadvantaged populations, the elderly, and those with preexisting chronic diseases (such as cardiovascular, pulmonary, renal, and psychiatric illnesses) have been consistently found to be vulnerable to heat waves across studies (Leung et al. 2008; Hajat et al. 2010; Chan et al. 2012a; Ibrahim et al. 2012; Arbuthnott and Hajat 2017; Ho et al. 2017). Several behavioral measures have been advised to reduce the heat-related health impacts and included in many action plans, including staying in air-conditioned places, using electric fans, drinking extra water/fluid, reducing vigorous physical activity, and avoid going out during the hottest hours in a hot day (Hajat et al. 2010; Gronlund 2014; Arbuthnott and Hajat 2017). However, an individual may not take those simple protective behaviors if he or she does not perceive heat waves as a threat. In fact, there are many health behavior models involving risk perception as an important element to explain behaviors or predict behavioral changes, such as the Theory of Reasoned Action, the Theory of Planned Behavior, and the Health Belief Model (Akompab et al. 2013; Ferrer and Klein 2015). Improvement of risk perception has therefore been considered as an intervention strategy to mitigate the health impacts of heat waves (Arbuthnott and Hajat 2017). There is a growing interest in examining associations between risk perception of and protective behaviors towards heat waves.

Findings across existing studies, however, are mixed. A household survey in five cities in Canada revealed that most participants perceived the heat as a health risk and would take coping actions, such as staying in air-conditioned places and keeping well hydrated (Alberini et al.
2011). Two cross-sectional studies in China reported that participants with high risk perception were more likely to undertake coping behaviors to heat waves (Liu et al. 2013; Ye et al. 2018). A theory-based survey among 267 Australian adults, however, did not find a significant relationship between perceived risk to a heat wave scenario and protective behaviors (Akompab et al. 2013). More studies are therefore warranted to gain a better understanding on this issue, which will have implications for developing effective strategies to strengthen health communication and other public health measures to reduce the health impacts of heat waves.

Hong Kong is a developed coastal city in the AsiaPacific region, characterized by high population density, high income inequality, and high average increases in urban ambient temperatures (Chan 2019). A significant long-term rising trend of extreme hot events was observed in Hong Kong during 1885-2008 (Wong et al. 2011). Annual highest or lowest daily maximum and minimum temperatures were found to increase by $0.09-0.14{ }^{\circ} \mathrm{C}$ per decade. Annual numbers of very hot days (daily maximum temperature $\geq 33.0^{\circ} \mathrm{C}$ ) and hot nights (daily minimum temperature $\geq 28.0^{\circ} \mathrm{C}$ ) increased by 0.9 days and 1.2 nights per decade respectively. Another study in southern China (including Hong Kong) revealed significant increases in frequency $(+0.19$ events per decade) and duration $(+2.86$ days per decade) of heat wave events in 1979-2010, which had accelerated after the 1990s (Luo and Lau 2017). Several studies in Hong Kong observed adverse health effects of heat waves on mortality, hospitalization, and health related help-seeking behavior, which are in line with most studies in other places (Leung et al. 2008; Hajat et al. 2010; Chan et al. 2011a; Chan et al. 2011b; Chan et al. 2012a; Yi and Chan 2015; Ho et al. 2017; Sun et al. 2018). For example, Chan et al. (2012a) reported that during $1998-2006$, a $1{ }^{\circ} \mathrm{C}$ increase in daily mean temperature above $28.2{ }^{\circ} \mathrm{C}$ was associated with a $1.8 \%$ increase in nonaccidental mortality. Another study analyzed data in 2002-2011 and found an elevated relative risk of $1.09(95 \%$ CI $1.03,1.17)$ in nonaccidental mortality at $31.5^{\circ} \mathrm{C}$ (the 99 th percentile of ambient temperature), compared to $27.8{ }^{\circ} \mathrm{C}$ (the 75 th percentile of temperature) for lags 0-3 (Yi and Chan 2015).

Hong Kong residents have started to be concerned about heat waves and their health consequences. Our previous population-based telephone survey revealed that Hong Kong residents perceived climate change as the first-order threat to their health among diverse natural and humanmade hazards and disasters (Chan et al. 2012b). However, no study in Hong Kong examined the relationship between the risk perception level of climate change and protective behaviors, although a better understanding of their relationship would be helpful to develop interventions that 
reduce adverse health impacts. In addition, while previous studies have suggested that appropriate use of cooling devices can effectively protect people from the heat, no such study has been conducted in Hong Kong. This study aims to investigate the ownership and utilization of home cooling devices (consisting of electric fans and air conditioners) among the general Hong Kong population aged 15 and above, identify related sociodemographic and other characteristics, and examine the association of these variables with perception of climate change health impact. Findings from the study will inform researchers, policymakers, and the public of the status of protective behaviors adopted by Hong Kong residents and identify those residents who are at high risk, which can be used to form effective policies and strategies against climate changes and heat waves.

\section{Methods}

This study used a population-based cross-sectional telephone survey, conducted among a representative sample of residents in Hong Kong from May to June 2012.

\subsection{Subjects}

The target population was the Cantonese-speaking, noninstitutionalized population aged 15 years and above residing in Hong Kong. There were 7.07 million noninstitutionalized residents $\geq 15$ years in Hong Kong in 2011 and about $95 \%$ of them used Cantonese as their usual language (Hong Kong Census and Statistics Department 2012). A random sample was recruited by telephone calls with a list of randomly generated telephone numbers. Over 95\% of the households in Hong Kong had a telephone line installed by 2012 (Chan et al. 2008; Chan et al. 2009; Lau et al. 2009). Telephone calls were made in the evening on weekdays (6:30 p.m. to 10:00 p.m., Monday to Friday) and during daytime on weekends (Saturday and Sunday) in order to avoid overrepresentation of people not working. An eligible member was selected from each of the contacted households. If more than one household member was eligible, the one whose birthday was closest to the survey date was invited to participate in the study. Verbal consent was obtained from the respondents in advance. At least five calls were dialled at different time slots before we considered the number invalid and gave up. All telephone interviews were conducted by two trained investigators.

Ethics approval was obtained from the Survey and Behavioural Research Ethics Committee at the Chinese University of Hong Kong. Verbal consent was obtained from the respondents above 18 years old and parental verbal consent was sought for those under 18 in advance.
Before the telephone interview started, the interviewers explained to the eligible participants the study purpose of the telephone survey and stated that strict confidentiality and anonymity of study participants was protected. Interviewees were also informed that they had the right to drop out of the study at any time during the interview. The consent procedure was approved by the ethics committee.

\subsection{Data Collection}

A structured questionnaire was developed to collect the participants' sociodemographic characteristics, ownership and use of cooling devices at home, perceived indoor temperature at which to turn on the cooling devices, and risk perception of the potential health impact of climate change. The questionnaire was pilot tested in April 2012 $(n=52$, male: $48 \%)$ and then was refined accordingly (Chan et al. 2012b).

Sociodemographic characteristics consisted of age, gender, district of residence, education level, occupation and employment status, type of housing, monthly household income, residence with vulnerable family members (that is, children under 15 years or elderly above 60 years), and presence of chronic diseases.

Ownership and use of cooling devices at home: Air conditioners and electric fans were considered as domestic cooling devices. Air conditioners could be all types, while electric fans could be ceiling fans, floor fans, table fans, wall-mounted fans, or window fans; exhaust fans (or similar devices) were excluded from the study due to their noncooling purposes. The participants were asked to respond to four questions with Yes or No: do you have air conditioners (or electric fans) at home (ownership of air conditioners or fans); usually, do you turn on the air conditioners (or electric fans) when you feel hot (use of air conditioners or fans)?

With respect to the perceived indoor temperature required to turn on cooling devices participants were asked if they had a perceived indoor temperature necessary to turn on the cooling devices or not. Specific temperatures (in degree Celsius) were further asked if yes. Participants were divided into two groups according to their reported temperatures being " $>$ " or " $\leq$ " two cut-off points-28 ${ }^{\circ} \mathrm{C}$ and $31^{\circ} \mathrm{C}$. We decided on the two cut-off points due to the following considerations; we found in previous studies that mortality and individual health-seeking behaviors were significantly and positively associated with temperature when values were above $28{ }^{\circ} \mathrm{C}$ and $31{ }^{\circ} \mathrm{C}$ respectively. That may roughly reflect the threshold temperatures causing health impacts by hot weather (Chan et al. 2011a).

To determine risk perception on potential health impacts of climate change, participants rated on an 11-point scale from 0 (do not worry at all) to 10 (extremely worried) their 
response to the question: "To what degree do you worry about the health risk of climate change?" They were then divided into low (0-5) and high (6-10) risk perception groups by the median value of 6 . It is an affective risk perception, measuring worry about a threat (Ferrer and Klein 2015). Evidence has shown that affective perceptions are related to preventive behaviors (Ferrer and Klein 2015).

\subsection{Statistical Analysis}

IBM SPSS Statistics (version 23) was used to analyze the data. Categorical data were presented by number and percentage. Both univariate and multivariate logistic regression models were fitted to estimate the risks of sociodemographic and other potential factors for ownership and use of the cooling devices before and after adjustment for each other. Only independent variables with $P<0.15$ in the univariate analyses were put into multivariate models and stepwisely selected in a forward manner (likelihood ratio) using $P<0.10$ and $P<0.15$ as entry and removal criteria. Unadjusted and adjusted odds ratios (ORs) and their $95 \%$ confidence intervals $(95 \% \mathrm{CI})$ were derived. In addition, a Chi square test was performed to examine the significance in difference between prevalence rate of not using air conditioners and that of not using fans in identified vulnerable subgroups of participants respectively, including those with the lowest monthly household income, the elderly, and those living with chronic diseases. We hypothesized that the risk perception would be associated with the utilization of cooling devices.

\section{Results}

A total of 11,034 telephone calls were dialled, of which $6653(60.3 \%)$ were invalid and $2790(25.3 \%)$ were not answered (Fig. 1). Of the remaining 1591 calls, 567 (35.6\%) refused to participate, and $22(1.4 \%)$ accepted invitation but did not complete the interview. Finally, 1002 $(63.0 \%)$ were successfully interviewed and with data analyzed. Table 1 presents the distribution of the characteristics in the sample and that in Hong Kong general population in 2011 where the statistics were available. Our sample was similar to the general population in the distribution of residence area, gender, age, and type of housing. However, more participants in our sample were married, with high education, and with a high monthly household income. In addition, more participants were professionals, clerical support workers, service and sales workers, and plant and machine operators, but fewer were associate professionals, craft and related workers, and elementary occupations. More than half of the participants lived with vulnerable family members (aged $<15$ or $>60$ years),

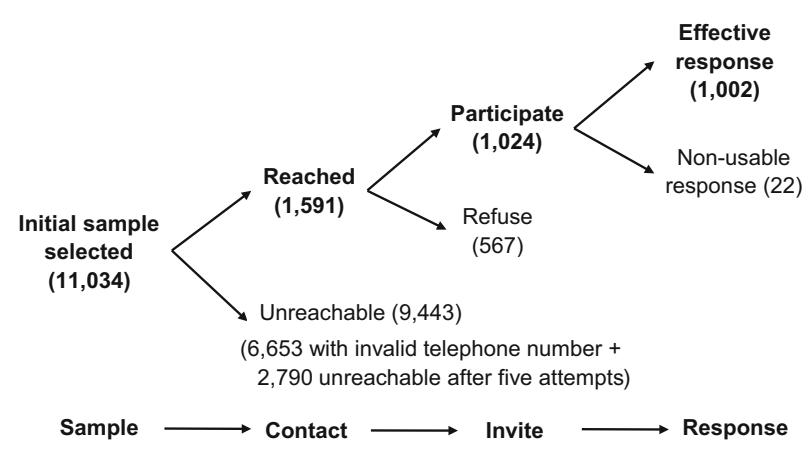

Fig. 1 The telephone survey sampling process used in the risk perception of climate change health impact survey in Hong Kong

$21.5 \%$ had chronic diseases, and $57.7 \%$ perceived the potential health risk of climate change at a high level (score range 6-10).

Most participants had air conditioners $(90.0 \%)$ or electric fans at home (90.3\%) (Table 2). The majority of the owners usually used air conditioners $(91.5 \%)$ and fans (95.1\%) when feeling hot. More than half of the participants $(54.3 \%)$ had perceived specific indoor temperatures at which to turn on the cooling devices, $58.1 \%$ and $95.4 \%$ of whom turned on the cooling devices at or below $28^{\circ} \mathrm{C}$ and $31{ }^{\circ} \mathrm{C}$ respectively.

Participants aged 65 years or above (unadjusted OR $2.39,95 \%$ CI $1.34-4.26, P=0.003)$, those with lower education (unadjusted OR of primary or below $2.83,95 \%$ CI $1.45-5.54, P=0.002$; unadjusted $\mathrm{OR}$ of secondary $2.06,95 \%$ CI $1.17-3.65, P=0.013)$, and those having chronic diseases (unadjusted OR 1.66, 95\% CI 1.05-2.62, $P=0.031$ ) were more likely to be living in a home without an air conditioner (Table 3). However, only education kept significant and stayed in the final model in the multivariate analysis. No independent variable was significantly associated with ownership of electric fans (Table 3).

Participants having religion (unadjusted OR 1.36, 95\% CI $1.03-1.80, P=0.028)$ and those having chronic diseases (unadjusted OR $1.58,95 \%$ CI $1.17-2.15, P=0.003$ ) were more likely to have no perceived specific temperature to turn on the cooling devices at home (Table 4). In the multivariate analysis, only the associations with religion (adjusted OR 1.32, 95\% CI 1.01-1.75, $P=0.049$ ) and chronic diseases (adjusted OR 1.51, 95\% CI 1.11-2.06, $P=0.009$ ) kept significant (Table 5). Among those who reported specific indoor temperature to turn on cooling devices, age (unadjusted OR of old adults $1.89,95 \% \mathrm{CI}$ $1.11-3.23, P=0.020$ ), education (unadjusted OR of primary or below $3.31,95 \%$ CI $1.84-5.93, P<0.001$ ), type of housing (unadjusted OR of subsidized housing 1.78, 95\% CI $1.10-2.88, P=0.020$; unadjusted OR of public housing 2.16 , 95\% CI 1.44-3.23, $P<0.001$ ), and monthly 
Table 1 Characteristics of the participants in the risk perception of climate change health impact survey in Hong Kong

\begin{tabular}{|c|c|c|c|}
\hline & \multicolumn{2}{|c|}{ The participants } & \multirow[t]{2}{*}{ Hong Kong census $(2011)^{\mathrm{a}}(\%)$} \\
\hline & $n$ & $\%$ & \\
\hline \multicolumn{4}{|l|}{ Area of residence $(N=962)$} \\
\hline Hong Kong island & 186 & 19.3 & 18.0 \\
\hline Kowloon & 291 & 30.2 & 29.8 \\
\hline New territories & 485 & 50.4 & 52.2 \\
\hline \multicolumn{4}{|l|}{ Gender $(N=1002)$} \\
\hline Male & 466 & 46.5 & 46.0 \\
\hline Female & 536 & 53.5 & 54.0 \\
\hline \multicolumn{4}{|l|}{ Age $(N=1002)$} \\
\hline $15-39$ years & 397 & 39.6 & 40.4 \\
\hline 40-64 years & 454 & 45.3 & 44.6 \\
\hline$\geq 65$ years & 151 & 15.1 & 15.1 \\
\hline \multicolumn{4}{|l|}{ Religion $(N=991)$} \\
\hline No & 711 & 71.7 & NA \\
\hline Yes & 280 & 28.3 & NA \\
\hline Christian & 143 & 14.4 & NA \\
\hline Catholic & 36 & 3.6 & NA \\
\hline Buddhist & 93 & 9.4 & NA \\
\hline Others & 8 & 0.8 & NA \\
\hline \multicolumn{4}{|l|}{ Marital status $(N=992)$} \\
\hline Married & 720 & 72.6 & 57.8 \\
\hline Single & 272 & 27.4 & 42.2 \\
\hline Never married & 252 & 25.4 & 31.6 \\
\hline Widowed & 12 & 1.2 & 6.2 \\
\hline Divorced & 6 & 0.6 & 3.9 \\
\hline Separated & 2 & 0.2 & 0.5 \\
\hline \multicolumn{4}{|l|}{ Education $(N=996)$} \\
\hline Primary or below & 158 & 15.9 & 22.7 \\
\hline Secondary ${ }^{\mathrm{b}}$ & 555 & 55.7 & 55.0 \\
\hline Tertiary & 283 & 28.4 & 22.3 \\
\hline \multicolumn{4}{|l|}{ Occupational status $(N=978)$} \\
\hline White collar ${ }^{\mathrm{c}}$ & 356 & 36.4 & NA \\
\hline Blue collar ${ }^{\mathrm{d}}$ & 90 & 9.2 & NA \\
\hline Students & 114 & 11.4 & NA \\
\hline Unemployed/retired/housewives & 418 & 42.7 & NA \\
\hline \multicolumn{4}{|l|}{ Occupation in working population $(N=446)$} \\
\hline Managers/administrators & 50 & 11.2 & 10.1 \\
\hline Professionals & 80 & 17.9 & 6.5 \\
\hline Associate professionals & 31 & 7.0 & 19.6 \\
\hline Clerical support workers & 95 & 21.3 & 15.6 \\
\hline Service and sales workers & 100 & 22.4 & 16.2 \\
\hline Craft and related workers & 5 & 1.1 & 7.4 \\
\hline Plant and machine operators & 44 & 9.9 & 5.0 \\
\hline Elementary occupations & 39 & 8.7 & 19.5 \\
\hline Skilled agricultural and fishery workers & 2 & 0.4 & 0.1 \\
\hline \multicolumn{4}{|l|}{ Type of housing $(N=966)$} \\
\hline Private housing & 505 & 52.3 & 51.8 \\
\hline Subsidized housing & 159 & 16.5 & 17.4 \\
\hline
\end{tabular}


Table 1 continued

\begin{tabular}{|c|c|c|c|}
\hline & \multicolumn{2}{|c|}{ The participants } & \multirow[t]{2}{*}{ Hong Kong census $(2011)^{\mathrm{a}}(\%)$} \\
\hline & $n$ & $\%$ & \\
\hline Public housing & 298 & 30.8 & 30.2 \\
\hline Temporary housing ${ }^{\mathrm{e}}$ & 4 & 0.4 & 0.7 \\
\hline \multicolumn{4}{|l|}{ Monthly household income $(N=690)$} \\
\hline$<\operatorname{HKD} 10,000(\approx$ USD 1280$)$ & 107 & 15.5 & 23.8 \\
\hline HKD 10,000-19,999 & 174 & 25.2 & 23.8 \\
\hline HKD 20,000-39,999 & 238 & 34.5 & 29.0 \\
\hline $\mathrm{HKD} \geq 40,000(\approx$ USD 5120$)$ & 171 & 24.8 & 23.5 \\
\hline \multicolumn{4}{|c|}{ Living with persons $<15$ or $>60$ years $(N=993)$} \\
\hline No & 416 & 41.9 & NA \\
\hline Yes & 577 & 58.1 & NA \\
\hline \multicolumn{4}{|l|}{ Having chronic diseases $(N=998)$} \\
\hline No & 783 & 78.5 & NA \\
\hline Yes & 215 & 21.5 & NA \\
\hline \multicolumn{4}{|c|}{ Risk perception of climate change health $\operatorname{impact}^{\mathrm{f}}(N=970)$} \\
\hline Low & 423 & 43.6 & NA \\
\hline High & 547 & 56.4 & NA \\
\hline
\end{tabular}

$N A$ no statistics available

${ }^{a}$ The percentages were derived from Hong Kong census in 2011 for the population aged 15 or above

${ }^{\mathrm{b}}$ Secondary education included diploma and certificate

${ }^{\mathrm{c}}$ White collar: including manager and administrators, professionals, associate professionals, clerical support workers, and service and sales workers

${ }^{\mathrm{d}}$ Blue collar: including craft and related workers, plant and machine operators, elementary occupations, and skilled agricultural and fishery workers

${ }^{\mathrm{e}}$ This type was combined with public housing in the later analyses to estimate the risk due to the small number of cases

${ }^{\mathrm{f}}$ Low risk perception of climate change health impact were those who rated the perceived health risk of climate change as $0-5$, while high risk perception were with a score of 6-10

household income (unadjusted OR of $<$ HKD 10,000 ( $\approx$ USD 1280) 2.99, 95\% CI 1.46-6.14, $P=0.003$; unadjusted OR of HKD 10,000-19,999 3.04, 95\% CI 1.67-5.54, $P<0.001$ ) were significantly related to such specific temperature at or below $28{ }^{\circ} \mathrm{C}$ in univariate analyses (Table 4), but only monthly household income met the variable selection criteria and stayed in the final multivariate logistic model. Education (unadjusted OR of primary or below 3.39 , 95\% CI $1.07-10.8, P=0.038$, Table 4) was the only variable significantly related with specific temperature at or below $31{ }^{\circ} \mathrm{C}$ in both univariate and multivariate analyses. Risk perception of climate change health impact had no relationship with any indicator of perceived temperature (Table 4).

Old adults (unadjusted OR 7.00, 95\% CI 3.66-13.4, $P<0.001$ ), those with the lowest education (unadjusted OR $3.97,95 \%$ CI $2.05-7.67, P<0.001$ ), those without a job (unemployed/retired/housewives, unadjusted OR 2.52, 95\% CI $1.41-4.51, P=0.002$ ), those living in public houses (unadjusted OR 2.03, 95\% CI 1.21-3.39,
$P=0.007)$, those having the lowest household income (unadjusted OR 7.71, 95\% CI 2.99-19.9, $P<0.001$ ), and those having chronic diseases (unadjusted OR 2.32, 95\% CI $1.40-3.86, P=0.003$ ) were more likely not to use air conditioners before adjustment for other factors (Table 6), whilst only monthly household income was kept in the final multivariate model. No factor studied was significantly related to use of fans in both univariate and multivariate analyses. Neither risk perception of climate change health risk nor perceived temperature to turn on cooling devices was associated with any behavior of cooling device use (Table 6).

\section{Discussion}

This telephone survey found high ownership and utilization rates of domestic cooling devices (both electric fans and air conditioners) among a representative population sample in Hong Kong. Around half of the participants reported a 
Table 2 Characteristics of ownership and use of cooling devices at home in the risk perception of climate change health impact survey in Hong Kong

\begin{tabular}{|c|c|c|}
\hline & $n$ & $\%$ \\
\hline \multicolumn{3}{|c|}{ Ownership of air conditioners $(N=999)$} \\
\hline No & 100 & 10.0 \\
\hline Yes & 899 & 90.0 \\
\hline \multicolumn{3}{|c|}{ Use of air conditioners when feeling $\operatorname{hot}^{\mathrm{a}}(N=875)$} \\
\hline No & 74 & 8.5 \\
\hline Yes & 801 & 91.5 \\
\hline \multicolumn{3}{|c|}{ Ownership of electric fans $(N=999)$} \\
\hline No & 97 & 9.7 \\
\hline Yes & 902 & 90.3 \\
\hline \multicolumn{3}{|c|}{ Use of electric fans when feeling hot ${ }^{\mathrm{b}}(N=878)$} \\
\hline No & 43 & 4.9 \\
\hline Yes & 835 & 95.1 \\
\hline \multicolumn{3}{|c|}{ Having perceived specific indoor temperature to use cooling devices $(N=998)$} \\
\hline No & 456 & 45.7 \\
\hline Yes & 542 & 54.3 \\
\hline \multicolumn{3}{|c|}{ Perceived specific indoor temperature to use cooling devices $(N=539)$} \\
\hline$\leq 28{ }^{\circ} \mathrm{C}$ & 313 & 58.1 \\
\hline $29-30{ }^{\circ} \mathrm{C}$ & 201 & 37.3 \\
\hline$>31{ }^{\circ} \mathrm{C}$ & 25 & 4.6 \\
\hline
\end{tabular}

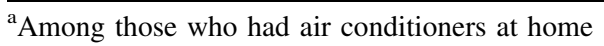

${ }^{\mathrm{b}}$ Among those who had electric fans at home

specific indoor temperature that they perceived necessary in order to turn on their cooling devices; of these participants, $58.1 \%$ and $95.4 \%$ usually turned their devices on at or below $28{ }^{\circ} \mathrm{C}$ and $31{ }^{\circ} \mathrm{C}$ respectively. Old people, those with lower education, those having lower household income, those living in public housing, and those with chronic diseases were more likely to live in a house without air conditioners. Even when owning an air conditioner, they were more likely not to turn on their home air conditioners when feeling hot. There was no significant relationship between ownership and utilization of fans and the sociodemographic factors studied. In addition, approximately three out of five participants perceived climate change as a high risk to health. Contrary to our hypothesis, the level of risk perception had no significant relationship with ownership and utilization of cooling devices.

In this study, we found that around nine out of 10 respondents had air conditioners at home and more than $90 \%$ of the owners used them in hot weather. Previous studies have suggested that utilization of air conditioners, as a cooling measure, has a strong protective effect and may be the leading protective factor against heat-related illness and death (Bouchama et al. 2007; Kenny et al. 2010). A meta-analysis on six studies published before 2007 (Bouchama et al. 2007) revealed that having air conditioners at home was associated with a relative risk reduction for heat-related death of $77 \%$ (OR $=0.23,95 \%$ $\mathrm{CI}=0.1-0.6)$. This result was further confirmed by a later review on another two studies, with both ORs being 0.2 (Kenny et al. 2010). The very high ownership and utilization rates found in the study sample suggest that overall the majority of Hong Kong population may have adopted the most effective means to reduce the health impact of heat. Nevertheless, we found that the respondents with the lowest education level, those with unemployed status, those living in public housing, and those with the lowest monthly household income were more likely not to use air conditioners, with the lowest household income having the strongest association (Table 6). Each of these characteristics at least partly reflects the poor socioeconomic status of a person, which is in line with previous studies that suggest financial conditions or financial considerations may be a major determinant of air conditioner use (Hansen et al. 2011). This fact may explain why the poor are at high risk for the health impact of heat waves, an observation noted also in other studies (Hajat et al. 2010; Kenny et al. 2010).

In addition, old people ( $\geq 65$ years) and those with chronic diseases were found more likely not to use air conditioners, which is consistent with most previous studies (Sheridan 2007; Abrahamson et al. 2009; Hansen et al. 
Table 3 Univariate logistic regression for ownership of cooling devices at home in the risk perception of climate change health impact survey in Hong Kong

\begin{tabular}{|c|c|c|c|c|c|c|}
\hline & \multicolumn{3}{|c|}{ Without an air conditioner } & \multicolumn{3}{|c|}{ Without an electric fan } \\
\hline & $n(\%)$ & $\mathrm{OR}_{\text {unadj }}(95 \% \mathrm{CI})$ & $P$ value & $n(\%)$ & $\mathrm{OR}_{\text {unadj }}(95 \% \mathrm{CI})$ & $P$ value \\
\hline Area of residence & & & 0.544 & & & 0.593 \\
\hline Hong Kong island (ref) & $15(8.1)$ & 1.00 & & $15(8.1)$ & 1.00 & \\
\hline Kowloon & $32(11.0)$ & $1.40(0.74,2.66)$ & 0.305 & $29(10.0)$ & $1.25(0.65,2.41)$ & 0.496 \\
\hline New territories & $52(10.8)$ & $1.37(0.75,2.50)$ & 0.308 & $52(10.8)$ & $1.37(0.75,2.50)$ & 0.308 \\
\hline \multicolumn{7}{|l|}{ Gender } \\
\hline Male (ref) & $50(10.8)$ & 1.00 & & $47(10.1)$ & 1.00 & \\
\hline Female & $50(9.3)$ & $0.85(0.57,1.29)$ & 0.453 & $50(9.3)$ & $0.91(0.60,1.39)$ & 0.677 \\
\hline Age & & & 0.012 & & & 0.242 \\
\hline 15-39 years (ref) & $29(7.3)$ & 1.00 & & $31(7.8)$ & 1.00 & \\
\hline 40-64 years & $47(10.4)$ & $1.47(0.91,2.38)$ & 0.120 & $48(10.6)$ & $1.40(0.87,2.25)$ & 0.164 \\
\hline$\geq 65$ years & $24(15.9)$ & $2.39 * *(1.34,4.26)$ & 0.003 & 18 (11.9) & $1.59(0.86,2.94)$ & 0.137 \\
\hline \multicolumn{7}{|l|}{ Religion } \\
\hline No (ref) & $68(9.6)$ & 1.00 & & $67(9.4)$ & 1.00 & \\
\hline Yes & $32(11.5)$ & $1.22(0.78,1.91)$ & 0.379 & $30(10.8)$ & $1.15(0.73,1.82)$ & 0.536 \\
\hline \multicolumn{7}{|l|}{ Marital status } \\
\hline Married (ref) & $72(10.0)$ & 1.00 & & $69(9.6)$ & 1.00 & \\
\hline Single & $28(10.3)$ & $0.97(0.61,1.53)$ & 0.887 & $28(10.3)$ & $0.92(0.58,1.47)$ & 0.734 \\
\hline Education & & & 0.008 & & & 0.123 \\
\hline Primary or below & $23(14.6)$ & $2.83 * *(1.45,5.54)$ & 0.002 & $16(10.1)$ & $1.56(0.78,3.13)$ & 0.210 \\
\hline Secondary & $61(11.0)$ & $2.06^{*}(1.17,3.65)$ & 0.013 & $62(11.2)$ & $1.75 *(1.02,2.99)$ & 0.041 \\
\hline Tertiary (ref) & $16(5.7)$ & 1.00 & & $19(6.7)$ & 1.00 & \\
\hline Occupational status & & & 0.161 & & & 0.476 \\
\hline White collar (ref) & $29(8.2)$ & 1.00 & & $30(8.5)$ & 1.00 & \\
\hline Blue collar & $6(6.7)$ & $0.80(0.32,2.00)$ & 0.637 & $7(7.8)$ & $0.91(0.39,2.15)$ & 0.836 \\
\hline Students & $11(9.7)$ & $1.21(0.59,2.51)$ & 0.605 & $11(9.7)$ & $1.17(0.57,2.41)$ & 0.674 \\
\hline Unemployed/retired/housewives & $52(12.5)$ & $1.60^{\#}(0.99,2.58)$ & 0.054 & $48(11.5)$ & $1.41(0.87,2.28)$ & 0.161 \\
\hline Type of housing & & & 0.773 & & & 0.505 \\
\hline Private housing (ref) & $52(10.4)$ & 1.00 & & $52(10.4)$ & 1.00 & \\
\hline Subsidised housing & $18(11.3)$ & $1.11(0.63,1.95)$ & 0.731 & $18(11.3)$ & $1.11(0.63,1.95)$ & 0.731 \\
\hline Public housing & $28(9.3)$ & $0.88(0.55,1.43)$ & 0.618 & $25(8.3)$ & $0.78(0.47,1.29)$ & 0.333 \\
\hline Monthly household income & & & 0.749 & & & 0.791 \\
\hline$<\operatorname{HKD} 10,000(\approx$ USD 1280$)$ & $14(13.2)$ & $1.22(0.58,2.55)$ & 0.601 & $11(10.4)$ & $0.83(0.38,1.79)$ & 0.630 \\
\hline HKD 10,000-19,999 & $16(9.2)$ & $0.81(0.40,1.63)$ & 0.556 & $16(9.2)$ & $0.72(0.36,1.44)$ & 0.356 \\
\hline HKD 20,000-39,999 & $24(10.1)$ & $0.90(0.48,1.70)$ & 0.749 & $23(9.7)$ & $0.77(0.41,1.44)$ & 0.409 \\
\hline $\mathrm{HKD} \geq 40,000(\approx$ USD 5120, ref $)$ & $19(11.1)$ & 1.00 & & $21(12.3)$ & 1.00 & \\
\hline \multicolumn{7}{|l|}{ Living with persons $<15$ or $>60$ years } \\
\hline No (ref) & $43(10.4)$ & 1.00 & & $45(10.9)$ & 1.00 & \\
\hline Yes & $54(9.4)$ & $0.89(0.59,1.36)$ & 0.598 & $49(8.5)$ & $0.76(0.50,1.17)$ & 0.212 \\
\hline \multicolumn{7}{|l|}{ Having chronic diseases } \\
\hline No (ref) & $70(9.0)$ & 1.00 & & $71(9.1)$ & 1.00 & \\
\hline Yes & $30(14.0)$ & $1.66^{*}(1.05,2.62)$ & 0.031 & $26(12.1)$ & $1.38(0.86,2.23)$ & 0.183 \\
\hline \multicolumn{7}{|c|}{ Risk perception of climate change health impact } \\
\hline Low (ref) & $48(11.3)$ & 1.00 & & $46(10.9)$ & 1.00 & \\
\hline High & $50(9.2)$ & $0.79(0.52,1.20)$ & 0.271 & $51(9.4)$ & $0.85(0.56,1.29)$ & 0.442 \\
\hline
\end{tabular}

${ }^{\#} P<0.1 ; * P<0.05 ; * * P<0.01 ; * * * P<0.0001$ 
Table 4 Univariate logistic regression for perceived temperature needed to turn on cooling devices at home in the risk perception of climate change health impact survey in Hong Kong

\begin{tabular}{|c|c|c|c|c|c|c|c|c|c|}
\hline & \multicolumn{3}{|c|}{ No perceived temperature } & \multicolumn{3}{|c|}{ Perceived temperature $>28^{\circ} \mathrm{C}$} & \multicolumn{3}{|c|}{ Perceived temperature $>31{ }^{\circ} \mathrm{C}$} \\
\hline & $n(\%)$ & $\begin{array}{l}\mathrm{OR}_{\text {unadj }}(95 \% \\
\mathrm{CI})\end{array}$ & $P$ value & $n(\%)$ & $\begin{array}{l}\text { OR }_{\text {unadj }}(95 \% \\
\text { CI) }\end{array}$ & $P$ value & $n(\%)$ & $\begin{array}{l}\mathrm{OR}_{\text {unadj }} \\
(95 \% \mathrm{CI})\end{array}$ & $P$ value \\
\hline Area of residence & & & 0.281 & & & 0.164 & & & 0.364 \\
\hline Hong Kong island (ref) & $81(43.5)$ & 1.00 & & $47(44.8)$ & 1.00 & & $7(6.7)$ & 1.00 & \\
\hline Kowloon & $123(42.4)$ & $\begin{array}{c}0.96(0.66 \\
1.39)\end{array}$ & 0.807 & $60(35.9)$ & $\begin{array}{l}0.69(0.42 \\
1.14)\end{array}$ & 0.147 & $5(3.0)$ & $\begin{array}{l}0.43(0.13 \\
1.40)\end{array}$ & 0.162 \\
\hline New territories & $231(47.9)$ & $\begin{array}{l}1.19(0.85 \\
1.68)\end{array}$ & 0.310 & $111(44.8)$ & $\begin{array}{l}1.00(0.63, \\
1.58)\end{array}$ & 0.999 & $13(5.2)$ & $\begin{array}{l}0.77(0.30 \\
2.00)\end{array}$ & 0.597 \\
\hline \multicolumn{10}{|l|}{ Gender } \\
\hline Male (ref) & $221(47.5)$ & 1.00 & & 99 (40.6) & 1.00 & & $10(4.1)$ & 1.00 & \\
\hline Female & $235(44.1)$ & $\begin{array}{l}0.87(0.68 \\
1.12)\end{array}$ & 0.277 & $127(43.1)$ & $\begin{array}{l}1.11(0.79 \\
1.56)\end{array}$ & 0.562 & $15(5.1)$ & $\begin{array}{l}1.25 \\
\quad(0.55,2.84)\end{array}$ & 0.589 \\
\hline Age & & & 0.211 & & & 0.066 & & & 0.470 \\
\hline $15-39$ years (ref) & $169(42.7)$ & 1.00 & & $87(38.5)$ & 1.00 & & $8(3.5)$ & 1.00 & \\
\hline 40-64 years & $212(46.7)$ & $\begin{array}{l}1.18(0.90 \\
1.54)\end{array}$ & 0.240 & $100(41.5)$ & $\begin{array}{l}1.13(0.78 \\
1.64)\end{array}$ & 0.509 & $12(5.0)$ & $\begin{array}{l}1.43(0.57 \\
3.56)\end{array}$ & 0.445 \\
\hline$\geq 65$ years & $75(50.7)$ & $\begin{array}{l}1.38^{\#}(0.95 \\
2.02)\end{array}$ & 0.096 & $39(54.2)$ & $\begin{array}{l}1.89 *(1.11 \\
3.23)\end{array}$ & 0.020 & $5(6.9)$ & $\begin{array}{l}2.03(0.64 \\
6.43)\end{array}$ & 0.227 \\
\hline \multicolumn{10}{|l|}{ Religion } \\
\hline No (ref) & $304(43.0)$ & 1.00 & & $172(43.0)$ & 1.00 & & $16(4.0)$ & 1.00 & \\
\hline Yes & $142(50.7)$ & $\begin{array}{l}1.36^{*}(1.03 \\
1.80)\end{array}$ & 0.028 & $53(38.4)$ & $\begin{array}{l}0.83(0.56 \\
1.23)\end{array}$ & 0.346 & $9(6.5)$ & $\begin{array}{l}1.67(0.72 \\
3.88)\end{array}$ & 0.229 \\
\hline \multicolumn{10}{|l|}{ Marital status } \\
\hline Married (ref) & $110(40.7)$ & 1.00 & & $57(36.1)$ & 1.00 & & $6(3.8)$ & 1.00 & \\
\hline Single & $341(47.5)$ & $\begin{array}{l}1.32^{\#}(0.99 \\
1.75)\end{array}$ & 0.058 & $167(44.4)$ & $\begin{array}{l}1.42^{\#}(0.97 \\
2.08)\end{array}$ & 0.075 & $19(5.1)$ & $\begin{array}{l}1.35(0.53 \\
3.44)\end{array}$ & 0.532 \\
\hline Education & & & 0.041 & & & $<0.001$ & & & 0.035 \\
\hline Primary or below & $82(52.6)$ & $\begin{array}{l}1.20(0.81 \\
1.77)\end{array}$ & 0.366 & $47(63.5)$ & $\begin{array}{l}3.31 * * *(1.84 \\
5.93)\end{array}$ & $<0.001$ & $8(10.8)$ & $\begin{array}{l}3.39 *(1.07 \\
10.8)\end{array}$ & 0.038 \\
\hline Secondary & $233(42.1)$ & $\begin{array}{c}0.79(0.59 \\
1.05)\end{array}$ & 0.103 & $129(40.4)$ & $\begin{array}{l}1.29(0.86 \\
1.94)\end{array}$ & 0.222 & $12(3.8)$ & $\begin{array}{l}1.09 \\
\quad(0.38,3.17)\end{array}$ & 0.868 \\
\hline Tertiary (ref) & $136(48.1)$ & 1.00 & & $50(34.5)$ & 1.00 & & $5(3.4)$ & 1.00 & \\
\hline Occupational status & & & 0.306 & & & 0.122 & & & 0.255 \\
\hline White collar (ref) & $162(45.5)$ & 1.00 & & $72(37.5)$ & 1.00 & & $5(2.6)$ & 1.00 & \\
\hline Blue collar & $45(50.0)$ & $\begin{array}{l}1.20(0.75 \\
1.90)\end{array}$ & 0.445 & $17(37.8)$ & $\begin{array}{c}1.01(0.52 \\
1.98)\end{array}$ & 0.972 & $4(8.9)$ & $\begin{array}{l}3.65^{\#}(0.94 \\
14.2)\end{array}$ & 0.062 \\
\hline Students & $43(37.7)$ & $\begin{array}{l}0.73(0.47 \\
1.12)\end{array}$ & 0.145 & $28(39.4)$ & $\begin{array}{l}1.09 \\
\quad(0.62,1.90)\end{array}$ & 0.774 & $3(4.2)$ & $\begin{array}{l}1.65(0.38 \\
7.09)\end{array}$ & 0.501 \\
\hline $\begin{array}{l}\text { Unemployed/ } \\
\text { retired/housewives }\end{array}$ & $192(46.4)$ & $\begin{array}{c}1.04(0.78 \\
1.38)\end{array}$ & 0.809 & $107(48.4)$ & $\begin{array}{l}1.56^{*}(1.06 \\
2.32)\end{array}$ & 0.026 & $13(5.9)$ & $\begin{array}{l}2.34(0.82 \\
\quad 6.68)\end{array}$ & 0.113 \\
\hline Type of housing & & & 0.191 & & & $<0.001$ & & & 0.860 \\
\hline Private housing (ref) & $218(43.3)$ & 1.00 & & $95(33.5)$ & 1.00 & & $12(4.2)$ & 1.00 & \\
\hline Subsidised housing & $69(43.4)$ & $\begin{array}{l}1.00(0.70 \\
1.44)\end{array}$ & 0.990 & $42(47.2)$ & $\begin{array}{l}1.78^{*}(1.10 \\
2.88)\end{array}$ & 0.020 & $5(5.6)$ & $\begin{array}{l}1.35(0.46 \\
3.94)\end{array}$ & 0.584 \\
\hline Public housing & $149(49.7)$ & $\begin{array}{c}1.29^{\#}(0.97 \\
1.72)\end{array}$ & 0.082 & $78(52.0)$ & $\begin{array}{l}2.16^{* * * *} \\
3.23)\end{array}$ & $<0.001$ & $7(4.7)$ & $\begin{array}{l}1.11(0.43, \\
2.88)\end{array}$ & 0.831 \\
\hline $\begin{array}{l}\text { Monthly household } \\
\text { income }\end{array}$ & & & 0.154 & & & $<0.001$ & & & 0.430 \\
\hline $\begin{array}{l}<\operatorname{HKD} 10,000(\approx \text { USD } \\
1280)\end{array}$ & $56(52.8)$ & $\begin{array}{l}1.40(0.86 \\
2.28)\end{array}$ & 0.175 & $26(52.0)$ & $\begin{array}{l}2.99 * *(1.46 \\
6.14)\end{array}$ & 0.003 & $2(4.0)$ & $\begin{array}{l}1.92(0.26 \\
14.0)\end{array}$ & 0.522 \\
\hline
\end{tabular}


Table 4 continued

\begin{tabular}{|c|c|c|c|c|c|c|c|c|c|}
\hline & \multicolumn{3}{|c|}{ No perceived temperature } & \multicolumn{3}{|c|}{ Perceived temperature $>28{ }^{\circ} \mathrm{C}$} & \multicolumn{3}{|c|}{ Perceived temperature $>31{ }^{\circ} \mathrm{C}$} \\
\hline & $n(\%)$ & $\begin{array}{l}\mathrm{OR}_{\text {unadj }}(95 \% \\
\mathrm{CI})\end{array}$ & $P$ value & $n(\%)$ & $\begin{array}{l}\mathrm{OR}_{\text {unadj }}(95 \% \\
\mathrm{CI})\end{array}$ & $P$ value & $n(\%)$ & $\begin{array}{l}\mathrm{OR}_{\text {unadj }} \\
(95 \% \mathrm{CI})\end{array}$ & $P$ value \\
\hline HKD 10,000-19,999 & $71(40.8)$ & $\begin{array}{c}0.86(0.56 \\
1.32)\end{array}$ & 0.494 & $54(52.4)$ & $\begin{array}{c}3.04 * * * \\
5.54)\end{array}$ & $<0.001$ & $7(6.8)$ & $\begin{array}{c}3.35(0.68, \\
16.6)\end{array}$ & 0.138 \\
\hline HKD 20,000-39,999 & $96(40.3)$ & $\begin{array}{l}0.85(0.57 \\
1.26)\end{array}$ & 0.407 & $49(34.5)$ & $\begin{array}{l}1.45(0.82 \\
2.58)\end{array}$ & 0.201 & $5(3.5)$ & $\begin{array}{l}1.68(0.32, \\
8.84)\end{array}$ & 0.541 \\
\hline $\begin{array}{l}\mathrm{HKD} \geq 40,000 \\
(\approx \text { USD } 5120, \text { ref })\end{array}$ & $76(44.4)$ & 1.00 & & $25(26.6)$ & 1.00 & & $2(2.1)$ & 1.00 & \\
\hline \multicolumn{10}{|c|}{ Living with persons $<15$ or $>60$ years } \\
\hline No (ref) & $185(44.7)$ & 1.00 & & $100(43.9)$ & 1.00 & & $13(5.7)$ & 1.00 & \\
\hline Yes & $267(46.4)$ & $\begin{array}{l}1.07(0.83 \\
1.38)\end{array}$ & 0.586 & $124(40.5)$ & $\begin{array}{l}0.87(0.62 \\
1.23)\end{array}$ & 0.440 & $12(3.9)$ & $\begin{array}{l}0.68(0.30 \\
1.51)\end{array}$ & 0.338 \\
\hline \multicolumn{10}{|l|}{ Having chronic diseases } \\
\hline No (ref) & $336(43.0)$ & 1.00 & & $181(40.9)$ & 1.00 & & $20(4.5)$ & 1.00 & \\
\hline Yes & $116(54.5)$ & $\begin{array}{l}1.58 * *(1.17 \\
2.15)\end{array}$ & 0.003 & $45(46.9)$ & $\begin{array}{l}1.28(0.82 \\
1.99)\end{array}$ & 0.279 & $5(5.2)$ & $\begin{array}{c}1.16(0.43, \\
3.18)\end{array}$ & 0.770 \\
\hline \multicolumn{10}{|c|}{ Risk perception of climate change health impact } \\
\hline Low (ref) & $192(45.7)$ & 1.00 & & $105(46.3)$ & 1.00 & & $14(6.2)$ & 1.00 & \\
\hline High & $241(44.1)$ & $\begin{array}{c}0.94(0.72 \\
1.21)\end{array}$ & 0.608 & $115(37.8)$ & $\begin{array}{l}0.71^{\#}(0.50 \\
1.00)\end{array}$ & 0.051 & $11(3.6)$ & $\begin{array}{c}0.57(0.25 \\
1.28)\end{array}$ & 0.175 \\
\hline
\end{tabular}

${ }^{\#} P<0.1 ; * P<0.05 ; * * P<0.01 ; * * * P<0.0001$

Table 5 Summary of multivariate logistic regression for no specific temperature to turn on cooling devices in the risk perception of climate change health impact survey in Hong Kong

\begin{tabular}{lll}
\hline & $\mathrm{OR}_{\text {adj }}(95 \% \mathrm{CI})$ & $P$ value \\
\hline $\begin{array}{ll}\text { Religion } \\
\text { No (ref) }\end{array}$ & 1.00 & \\
Yes & $1.32 *(1.01,1.75)$ & 0.049 \\
Having chronic diseases & & \\
No (ref) & 1.00 & 0.009 \\
Yes & $1.51^{* *}(1.11,2.06)$ &
\end{tabular}

$* P<0.05 ; * * P<0.01$

2011; White-Newsome et al. 2011). Personal perceptions of heat are crucial in shaping individual adaptive behaviors. When people perceived that adaptation to hot weather is unnecessary, they make few to no behavior adjustments to prevent heat-related health risks (White-Newsome et al. 2011). The diminished perception of heat among the elderly is a major barrier to their ability to take heat-related, risk-reduction actions (Hansen et al. 2011). Thermoregulatory impairment, chronic diseases, and dehydration and drug effects among the elderly further enhance their risk of heat exposure (Koppe 2004). In addition, chronic medical conditions significantly alter the body's physiologic response to heat load or the ability to tolerate changes in core body temperature (Allen and Segal-Gidan 2007). Cardiovascular diseases, for example, are the most significant condition that predisposes sufferers to heat illness. Other chronic conditions include obesity, hyperthyroidism, psychiatric disorders, and extensive skin diseases or damages (Allen and Segal-Gidan 2007). Thus, it is of utmost importance to empower the elderly and those having chronic diseases by effective interventions to undertake adaptive behaviors during extreme heat to maintain thermal comfort and avoid heat stress.

We did not find any factor studied in this research that was significantly associated with the ownership and utilization of electric fans, though these two rates were similarly as high as those experienced by owners and users of air conditioners. Prices of electric fans, as low as HKD 50 (USD 6.44) for a secondhand working fan and HKD 200 (USD 25.8) for a new one, may be affordable even for the disadvantaged in Hong Kong for whom the median monthly household income in 2011 was HKD 20,500 (that is, USD 2640). In addition, previous studies indicated that the elderly and those with chronic diseases were more likely to use fans than air conditioners as ways for adapting to heat (Sheridan 2007; Abrahamson et al. 2009; WhiteNewsome et al. 2011). In our study, near one quarter of the 123 elderly who responded to the question $(24.4 \%, n=30)$ did not turn air conditioners on when feeling hot, quintuple of the proportion of not using fans $(5.4 \%$, that is, 7 out of 
Table 6 Univariate logistic regression for use of cooling devices at home when feeling hot in the risk perception of climate change health impact survey in Hong Kong

\begin{tabular}{|c|c|c|c|c|c|c|}
\hline & \multicolumn{3}{|c|}{ Not use air conditioners } & \multicolumn{3}{|c|}{ Not use electric fans } \\
\hline & $n(\%)$ & $\mathrm{OR}_{\text {unadj }}(95 \% \mathrm{CI})$ & $P$ value & $n(\%)$ & $\mathrm{OR}_{\text {unadj }}(95 \% \mathrm{CI})$ & $P$ value \\
\hline Area of residence & & & 0.443 & & & 0.470 \\
\hline Hong Kong island (ref) & $10(5.9)$ & 1.00 & & $10(5.9)$ & 1.00 & \\
\hline Kowloon & $23(9.1)$ & $1.60(0.74,3.45)$ & 0.233 & $9(3.5)$ & $0.58(0.23,1.46)$ & 0.250 \\
\hline New territories & $37(8.9)$ & $1.55(0.75,3.19)$ & 0.236 & $22(5.3)$ & $0.89(0.41,1.91)$ & 0.757 \\
\hline \multicolumn{7}{|l|}{ Gender } \\
\hline Male (ref) & $32(8.0)$ & 1.00 & & $17(4.2)$ & 1.00 & \\
\hline Female & $42(8.8)$ & $1.12(0.69,1.80)$ & 0.656 & $26(5.5)$ & $1.32(0.70,2.46)$ & 0.392 \\
\hline Age & & & $<0.001$ & & & 0.818 \\
\hline 15-39 years (ref) & $16(4.4)$ & 1.00 & & $19(5.3)$ & 1.00 & \\
\hline 40-64 years & $28(7.2)$ & $1.68(0.89,3.16)$ & 0.107 & $17(4.4)$ & $0.83(0.42,1.61)$ & 0.573 \\
\hline$\geq 65$ years & $30(24.4)$ & $7.00 * * *(3.66,13.4)$ & $<0.001$ & $7(5.4)$ & $1.03(0.42,2.52)$ & 0.943 \\
\hline \multicolumn{7}{|l|}{ Religion } \\
\hline No (ref) & $51(8.1)$ & 1.00 & & $28(4.4)$ & 1.00 & \\
\hline Yes & $22(9.3)$ & $1.17(0.69,1.97)$ & 0.563 & $14(5.9)$ & $1.35(0.70,2.60)$ & 0.377 \\
\hline \multicolumn{7}{|l|}{ Marital status } \\
\hline Married (ref) & $16(6.6)$ & 1.00 & & $15(6.2)$ & 1.00 & \\
\hline Single & $58(9.3)$ & $1.44(0.81,2.56)$ & 0.215 & $28(4.5)$ & $0.70(0.37,1.34)$ & 0.285 \\
\hline Education & & & $<0.001$ & & & 0.865 \\
\hline Primary or below & $27(20.8)$ & $3.97 * * *(2.05,7.67)$ & $<0.001$ & $8(5.8)$ & $1.26(0.50,3.15)$ & 0.627 \\
\hline Secondary & $30(6.2)$ & $1.00(0.54,1.88)$ & 0.990 & $23(4.8)$ & $1.02(0.50,2.08)$ & 0.963 \\
\hline Tertiary (ref) & $16(6.2)$ & 1.00 & & $12(4.7)$ & 1.00 & \\
\hline Occupational status & & & 0.005 & & & 0.106 \\
\hline White collar (ref) & $17(5.3)$ & 1.00 & & $10(3.1)$ & 1.00 & \\
\hline Blue collar & $8(9.9)$ & $1.95(0.81,4.69)$ & 0.137 & $3(3.8)$ & $1.20(0.32,4.47)$ & 0.786 \\
\hline Students & $4(4.0)$ & $0.74(0.24,2.25)$ & 0.596 & $9(9.0)$ & $3.05 *(1.20,7.72)$ & 0.019 \\
\hline Unemployed/retired/housewives & $44(12.4)$ & $2.52 * *(1.41,4.51)$ & 0.002 & $21(5.9)$ & $1.92^{\#}(0.89,4.14)$ & 0.096 \\
\hline Type of housing & & & 0.010 & & & 0.117 \\
\hline Private housing (ref) & $30(6.9)$ & 1.00 & & $27(6.2)$ & 1.00 & \\
\hline Subsidized housing & $8(5.8)$ & $0.84(0.38,1.88)$ & 0.674 & $2(1.5)$ & $0.23 *(0.05,0.96)$ & 0.044 \\
\hline Public housing & $35(13.0)$ & $2.03 * *(1.21,3.39)$ & 0.007 & $13(4.8)$ & $0.76(0.39,1.50)$ & 0.434 \\
\hline Monthly household income & & & $<0.001$ & & & 0.261 \\
\hline$<\operatorname{HKD} 10,000(\approx$ USD 1280) & $22(24.4)$ & $7.71 * * *(2.99,19.9)$ & $<0.001$ & $5(5.4)$ & $1.14(0.35,3.69)$ & 0.832 \\
\hline HKD 10,000-19,999 & $10(6.5)$ & $1.67(0.59,4.71)$ & 0.335 & $7(4.6)$ & $0.96(0.33,2.80)$ & 0.939 \\
\hline HKD 20,000-39,999 & $7(3.4)$ & $0.84(0.28,2.55)$ & 0.756 & $3(1.4)$ & $0.29^{\#}(0.08,1.16)$ & 0.080 \\
\hline $\mathrm{HKD} \geq 40,000(\approx$ USD 5120, ref $)$ & $6(4.0)$ & 1.00 & & $7(4.8)$ & 1.00 & \\
\hline \multicolumn{7}{|l|}{ Living with persons $<15$ or $>60$ years } \\
\hline No (ref) & $34(9.4)$ & 1.00 & & $23(6.4)$ & 1.00 & \\
\hline Yes & $39(7.7)$ & $0.80(0.50,1.30)$ & 0.369 & $20(3.9)$ & $0.59^{\#}(0.32,1.10)$ & 0.097 \\
\hline \multicolumn{7}{|l|}{ Having chronic diseases } \\
\hline No (ref) & $48(6.9)$ & 1.00 & & $36(5.2)$ & 1.00 & \\
\hline Yes & $26(14.7)$ & $2.32 * *(1.40,3.86)$ & 0.001 & $6(3.3)$ & $0.63(0.26,1.51)$ & 0.298 \\
\hline \multicolumn{7}{|c|}{ Risk perception of climate change health impact } \\
\hline Low (ref) & $36(9.7)$ & 1.00 & & $22(5.9)$ & 1.00 & \\
\hline High & $32(6.7)$ & $0.67(0.41,1.10)$ & 0.110 & $19(4.0)$ & $0.66(0.35,1.24)$ & 0.198 \\
\hline \multicolumn{7}{|c|}{ Having perceived specific temperature to turn on cooling devices } \\
\hline Yes (ref) & $33(7.3)$ & 1.00 & & $16(3.5)$ & 1.00 & \\
\hline
\end{tabular}


Table 6 continued

\begin{tabular}{|c|c|c|c|c|c|c|}
\hline & \multicolumn{3}{|c|}{ Not use air conditioners } & \multicolumn{3}{|c|}{ Not use electric fans } \\
\hline & $n(\%)$ & $\mathrm{OR}_{\text {unadj }}(95 \% \mathrm{CI})$ & $P$ value & $n(\%)$ & $\mathrm{OR}_{\text {unadj }}(95 \% \mathrm{CI})$ & $P$ value \\
\hline No & $39(9.2)$ & $1.28(0.79,2.07)$ & 0.322 & $26(6.1)$ & $1.78^{\#}(0.94,3.37)$ & 0.076 \\
\hline \multicolumn{7}{|c|}{ Perceived temperature to turn on cooling devices } \\
\hline$\leq 28{ }^{\circ} \mathrm{C}(\mathrm{ref})$ & $18(6.8)$ & 1.00 & & $12(4.5)$ & 1.00 & \\
\hline$>28{ }^{\circ} \mathrm{C}$ & $15(8.2)$ & $1.23(0.60,2.50)$ & 0.573 & $4(2.2)$ & $0.48(0.15,1.52)$ & 0.213 \\
\hline
\end{tabular}

${ }^{\#} P<0.1 ; * P<0.05 ; * * P<0.01 ; * * * P<0.0001$

the 129 elderly respondents, Table 6), which agrees with the previous studies (Sheridan 2007; Abrahamson et al. 2009; Hansen et al. 2011; White-Newsome et al. 2011). A similar pattern was also found among those participants with chronic diseases of whom 14.7\%; (26 out of 177) did not use air conditioners versus $3.3 \%$ (6 of 181) who did not use fans (Table 6). It has been suggested that the use of air conditioners may be unsustainable in a warming climate because of the positive feedback loop they create through their high energy consumption, which will further add to climate change by increasing emissions, the increased risk of blackouts due to pressures on the energy grid, and their high operational cost (Gupta et al. 2012). Proper use of electric fans might be a promising and sustainable alternative that might help to reduce the health impact of heat. But further studies should be focused on electric fan use during heat waves to explore this possibility. In this study, all elderly and those individuals with chronic diseases who did not use fans also did not use air conditioners. Those people may be extremely vulnerable to climate changes and more attention should be paid to this population subset in future research.

Contrary to our hypothesis, we did not find positive relationship between risk perception level of climate change health impact and cooling device ownership and use. It is possible that we may have missed other protective ways against heat undertaken by the participants (for example, visits to other air conditioned places), which may result in the insignificant relationship. It is also likely that although some people have realized that heat waves are a health threat, they may have not moved from the "awareness" stage into the "practice" stage due to a variety of reasons (for example, insufficient knowledge about adaptive ways to counter heat; lack of intention to undertake potential actions). Nevertheless, comprehensive surveys that focus on both physiological and environmental factors during a heat wave would be helpful in revealing the relationship between risk perception and mitigation behaviors against heat.

The results of this study should be considered within its limitations. First and foremost, the study encounters the potential limitations of similar cross-sectional studies. For example, we cannot draw a conclusion on the cause-effect relationship and reported information may suffer from recall bias. The results are subjected to the respondents' own perception of the risk and their subjective assessment of the degree of that risk, and therefore it is likely that the same score across different participants may have different meanings. Second, as a telephone survey, we have missed people who have no land-based telephone at home (about $5 \%$ of households). Those people may be quite different from our sample from the standpoint of sociodemographic characteristics as well as in terms of the ownership and utilization of home cooling devices. Given that most people without land-line phones are poor or disadvantaged (Hong Kong Census and Statistics Department 2012), and the poor are the most vulnerable population to heat wave impacts, further studies should address them using appropriate recruitment methods (for example, home visits to those living in subdivided flats). Moreover, we conducted this study in May and June, when Hong Kong summer had just begun (summer time in Hong Kong is from May to September, with June to August being the hottest months). According to the Hong Kong Observatory, there was no extreme hot event or heat wave in the months before and during the study period. Thus, it is likely to result in bias if our results are applied to the results to other periods with hot summers or heat waves. Further studies during or right after heat waves are therefore needed to confirm our findings. Last but not the least, we focused on utilization of cooling devices at home only and did not examine other protective behaviors such as visiting public air-conditioned places. We therefore cannot exclude the possibility that participants with high risk perception might reduce the health impact of heat waves through other means than using cooling devices at home (for example, staying in communal or extended family air-conditioned environments). It would be essential to clarify alternative access relationships by conducting studies in the future to comprehensively investigate personal heat protection behaviors. 


\section{Conclusion}

Our findings suggest that the majority of Hong Kong residents have air conditioners or electric fans at home. Yet familial economic condition is a major determinant of ownership and use of home air conditioners. Old people and those with chronic diseases are at high risk of climate change health impact and therefore should be equipped with appropriate measures to access cooling devices. Although more than half of the general population in Hong Kong recognized climate change as a threat to health, there are no signs in this study that show they have taken more protective actions. Further studies should be conducted to address electric fan use with a focus on people in poor. Our findings have important implications for the development of evidence-based policy initiatives and effective action plans to mitigate the health impact of heat waves. The identified vulnerable populations should become the focus of reorganization and implementation of relevant public heath, medical, and social services. For example, outreach services and home visits for the poor, the elderly, and those living with chronic diseases may help to protect them from the health impacts of heat waves. Health care workers and social workers should also be empowered with appropriate knowledge and skills related to heat waves and appropriate protective health measures. It takes multidisciplinary collaboration and action to reduce heat-related health impacts. Improvement of risk perception alone may not be able to increase personal behavioral measures. Thus, other effective strategies should be considered (such as outreach services). Given that there is a gap in the evidence of effectiveness of existing heat wave plans, well-designed evaluation studies are warranted in the future (Arbuthnott and Hajat 2017).

Acknowledgements We gratefully acknowledge the time and efforts given by the telephone survey interviewers and Ms. Janice Yue and Ms. Poyi Lee for data collection, various stages of data analysis, and initial study writing. This research project was cofunded by the Chinese University of Hong Kong (CUHK) Focused Innovations Scheme-Scheme A: Biomedical Sciences (Phase 2) and the CUHK Climate Change and Health research project fund. The funders had no role in study design, data collection and analysis, decision to publish, or preparation of the manuscript.

Open Access This article is licensed under a Creative Commons Attribution 4.0 International License, which permits use, sharing, adaptation, distribution and reproduction in any medium or format, as long as you give appropriate credit to the original author(s) and the source, provide a link to the Creative Commons licence, and indicate if changes were made. The images or other third party material in this article are included in the article's Creative Commons licence, unless indicated otherwise in a credit line to the material. If material is not included in the article's Creative Commons licence and your intended use is not permitted by statutory regulation or exceeds the permitted use, you will need to obtain permission directly from the copyright holder. To view a copy of this licence, visit http://creativecommons. org/licenses/by/4.0/.

\section{References}

Abrahamson, V., J. Wolf, I. Lorenzoni, B. Fenn, S. Kovats, P. Wilkinson, W.N. Adger, and R. Raine. 2009. Perceptions of heatwave risks to health: Interview-based study of older people in London and Norwich, UK. Journal of Public Health 31(1): 119-126.

Akompab, D.A., P. Bi, S. Williams, J. Grant, I.A. Walker, and M. Augoustinos. 2013. Heat waves and climate change: Applying the health belief model to identify predictors of risk perception and adaptive behaviours in Adelaide, Australia. International Journal of Environmental Research and Public Health 10(6): 2164-2184.

Alberini, A., W. Gans, and M. Alhassan. 2011. Individual and publicprogram adaptation: Coping with heat waves in five cities in Canada. International Journal of Environmental Research and Public Health 8(12): 4679-4701.

Allen, A., and F. Segal-Gidan. 2007. Heat related illness in the elderly. Clinical Geriatrics 15(7): 37-45.

Arbuthnott, K.G., and S. Hajat. 2017. The health effects of hotter summers and heat waves in the population of the United Kingdom: A review of the evidence. Environmental Health: A Global Access Science Source 16(Suppl 1): 1-13.

Bouchama, A., M. Dehbi, G. Mohamed, F. Matthies, M. Shoukri, and B. Menne. 2007. Prognostic factors in heat wave related deaths: A meta-analysis. Archives of Internal Medicine 167(20): 2170-2176.

Chan, E.Y.Y. 2019. Climate change and urban health: The case of Hong Kong as a subtropical city. London: Routledge.

Chan, E.Y.Y., J.H. Kim, Q. Ng, S. Griffiths, and J.T.F. Lau. 2008. A descriptive study of nonfatal, unintentional home-based injury in urban settings: Evidence from Hong Kong. Asia Pacific Journal of Public Health 20(Suppl): 39-48.

Chan, E.Y.Y., J.H. Kim, S.M. Griffiths, J.T.F. Lau, and I. Yu. 2009. Does living density matter for nonfatal unintentional home injury in Asian urban settings? Evidence from Hong Kong. Journal of Urban Health 86(6): 872-886.

Chan, E.Y.Y., W.B. Goggins, J.J. Kim, S. Griffiths, and T.K.W. Ma. 2011a. Help-seeking behavior during elevated temperature in Chinese population. Journal of Urban Health 88(4): 637-650.

Chan, E.Y.Y., J. Kim, P. Lee, and C. Lin. 2011b. Analysis of health risk perception and behavior changes during elevated temperatures for an urban Chinese population. Prehospital and Disaster Medicine 26(S1). https://doi.org/10.1017/s1049023x11000914.

Chan, E.Y.Y., W.B. Goggins, J.J. Kim, and S.M. Griffiths. 2012a. A study of intracity variation of temperature-related mortality and socioeconomic status among the Chinese population in Hong Kong. Journal of Epidemiology and Community Health 66(4): 322-327.

Chan, E.Y.Y., K.K.C. Hung, J.S.K. Yue, J.H. Kim, P.P.Y. Lee, and E.Y.L. Cheung. 2012b. Preliminary findings on urban disaster risk literacy and preparedness in a Chinese community. Presented in the 13th World Congress of Public Health "Towards Global Health Equity: Opportunities and Threats", 23-27 April, Addis Ababa, Ethiopia.

Ferrer, R.A., and W.M.P. Klein. 2015. Risk perceptions and health behavior. Current Opinion in Psychology 5: 85-89.

Fouillet, A., G. Rey, V. Wagner, K. Laaidi, P. Empereur-Bissonnet, A. LeTertre, P. Frayssinet, et al. 2008. Has the impact of heat waves on mortality changed in France since the european heat 
wave of summer 2003? A study of the 2006 heat wave. International Journal of Epidemiology 37(2): 309-317.

Gronlund, C.J. 2014. Racial and socioeconomic disparities in heatrelated health effects and their mechanisms: A review. Current Epidemiology Reports 1(3): 165-173.

Gupta, S., C. Carmichael, C. Simpson, M.J. Clarke, C. Allen, Y. Gao, E.Y.Y. Chan, and V. Murray. 2012. Electric fans for reducing adverse health impacts in heatwaves. Cochrane Database of Systematic Reviews 7: CD009888. https://doi.org/10.1002/ 14651858.cd009888.pub2.

Hajat, S., M. O'Connor, and T. Kosatsky. 2010. Health effects of hot weather: From awareness of risk factors to effective health protection. The Lancet 375(9717): 856-863.

Hansen, A., P. Bi, M. Nitschke, D. Pisaniello, J. Newbury, and A. Kitson. 2011. Perceptions of heat-susceptibility in older persons: Barriers to adaptation. International Journal of Environmental Research and Public Health 8(12): 4714-4728.

Ho, H.C., K.K.-L. Lau, C. Ren, and E. Ng. 2017. Characterizing prolonged heat effects on mortality in a sub-tropical high-density city, Hong Kong. International Journal of Biometeorology 61(11): 1935-1944.

Hong Kong Census and Statistics Department. 2012. 2011 population census. Publications Unit of the Census and Statistics Department; Government of the Hong Kong Special Administrative Region. http://www.censtatd.gov.hk/. Accessed 12 Dec 2018.

Ibrahim, J.E., J.A. McInnes, N. Andrianopoulos, and S. Evans. 2012. Minimising harm from heatwaves: A survey of awareness, knowledge, and practices of health professionals and care providers in Victoria, Australia. International Journal of Public Health 57(2): 297-304.

IPCC (Intergovernmental Panel on Climate Change). 2012. Summary for policymakers. In Managing the risks of extreme events and disasters to advance climate change adaptation. A special report of working groups I and II of the Intergovernmental Panel on Climate Change, ed. C.B. Field, V. Barros, T.F. Stocker, D. Qin, D.J. Dokken, K.L. Ebi, M.D. Mastrandrea, K.J. Mach, G.-K. Plattner, S.K. Allen, M. Tignor, and P.M. Midgley, 1-19. Cambridge and New York: Cambridge University Press.

IPCC (Intergovernmental Panel on Climate Change). 2018. Summary for policymakers. In Global warming of $1.5^{\circ} \mathrm{C}$. An IPCC special report on the impacts of global warming of $1.5^{\circ} \mathrm{C}$ above preindustrial levels and related global greenhouse gas emission pathways, in the context of strengthening the global response to the threat of climate change, sustainable development, and efforts to eradicate poverty, ed.V. Masson-Delmotte, P. Zhai, H. O. Pörtner, D. Roberts, J. Skea, P.R. Shukla, A. Pirani, W. Moufouma-Okia, C. Péan, R. Pidcock, S. Connors, J. B. R. Matthews, Y. Chen, X. Zhou, M. I. Gomis, E. Lonnoy, T. Maycock, M. Tignor, T. Waterfield, 1-24. Geneva: World Meteorological Organization.

Kenny, G.P., J. Yardley, C. Brown, R.J. Sigal, and O. Jay. 2010. Heat stress in older individuals and patients with common chronic diseases. Canadian Medical Association Journal 182(10): 1053-1060.

Koppe, C., S. Kovats, G. Jendritzky, and B. Menne. 2004. Heatwaves: Risks and responses. Health and Global Environmental Change. Series, No. 2. Copenhagen: WHO Regional Office for Europe.

Lau, J.T.F., N.C.Y. Yeung, K.C. Choi, M.Y.M. Cheng, H.Y. Tsui, and S. Griffiths. 2009. Acceptability of A/H1N1 vaccination during pandemic phase of influenza A/H1N1 in Hong Kong: Population based cross sectional survey. BMJ 339(7728): Article 1014.

Leung, Y.K., K.M. Yip, and K.H. Yeung. 2008. Relationship between thermal index and mortality in Hong Kong. Meteorological Applications 15(3): 399-409.

Liu, T., Y.J. Xu, Y.H. Zhang, Q.H. Yan, X.L. Song, H.Y. Xie, Y. Luo, S. Rutherford, C. Chu, H.L. Lin, and W.J. Ma. 2013. Associations between risk perception, spontaneous adaptation behavior to heat waves and heatstroke in Guangdong province, China. BMC Public Health 13(1): Article 913.

Luo, M., and N.C. Lau. 2017. Heat waves in Southern China: Synoptic behavior, long-term change, and urbanization effects. Journal of Climate 30(2): 703-720.

Mora, C., B. Dousset, I.R. Caldwell, F.E. Powell, R.C. Geronimo, C.R. Bielecki, C.W.W. Counsell, et al. 2017. Global risk of deadly heat. Nature Climate Change 7(7): 501-506.

Robine, J.M., S.L.K. Cheung, S. Le Roy, H. Van Oyen, C. Griffiths, J.-P. Michel, and F.R. Herrmann. 2008. Death toll exceeded 70,000 in Europe during the summer of 2003. Comptes Rendus Biologies 331(2): 171-178.

Sheridan, S.C. 2007. A survey of public perception and response to heat warnings across four North American cities: An evaluation of municipal effectiveness. International Journal of Biometeorology 52(1): 3-15.

Sun, S., F. Laden, J.E. Hart, H. Qiu, Y. Wang, C.M. Wong, R.S. Lee, and L. Tian. 2018. Seasonal temperature variability and emergency hospital admissions for respiratory diseases: A populationbased cohort study. Thorax 73(4): 951-958.

UN General Assembly. 2015. Transforming our world: The 2030 agenda for sustainable development. A/RES/70/1. https://www. refworld.org/docid/57b6e3e44.html. Accessed 3 Jul 2019.

White-Newsome, J.L., B.N. Sánchez, E.A. Parker, J.T. Dvonch, Z. Zhang, and M.S. O'Neill. 2011. Assessing heat-adaptive behaviors among older, urban-dwelling adults. Maturitas 70(1): 85-91.

Wong, M.C., H.Y. Mok, and T.C. Lee. 2011. Observed changes in extreme weather indices in Hong Kong. International Journal of Climatology 31(15): 2300-2311.

Ye, H., J. Ma, Y. Wu, and Y. Zhang. 2018. Perceptions of health risks from hot weather, and coping behaviors among ethnic minority groups in mountain areas of China: A case study in the Tujia and Miao autonomous prefecture. International Journal of Environmental Research and Public Health 15(11): Article 2498.

Yi, W., and A.P.C. Chan. 2015. Effects of temperature on mortality in Hong Kong: A time series analysis. International Journal of Biometeorology 59(7): 927-936. 